Tropical Journal of Pharmaceutical Research September 2014; 13 (9): 1503-1510

ISSN: $1596-5996$ (print); 1596-9827 (electronic)

(c) Pharmacotherapy Group, Faculty of Pharmacy, University of Benin, Benin City, 300001 Nigeria.

All rights reserved.

Available online at http://www.tjpr.org

Original Research Article

http://dx.doi.org/10.4314/tjpr.v13i9.17

\title{
Development and Validation of Liquid Chromatography- Mass Spectroscopy/Mass Spectroscopy Method for Quantitative Analysis of Naproxen in Human Plasma after Liquid-Liquid Extraction
}

\author{
NK Sahoo ${ }^{1 *}$, M Sahu ${ }^{1}$, PS Rao ${ }^{1}$ and G Ghosh ${ }^{2}$ \\ ${ }^{1}$ Yalamarty Pharmacy College, Tarluwada, Visakhapatnam. Andhra Pradesh, 530052, ${ }^{2}$ School of Pharmaceutical Sciences, \\ Siksha 'O' Anusandhan University, Bhubaneswar, Odisha, 751003, India
}

*For correspondence: Email: sahoo.nalini@gmail.com; Tel: 09550741536,09396772373

Received: 3 December 2013

Revised accepted: 28 July 2014

\begin{abstract}
Purpose: To determine naproxen levels in human plasma using a new liquid chromatography-Mass spectroscopy/Mass spectroscopy (LC-MS/MS) method that involves a simple and single step extraction procedure using low-cost reagents.

Method: A novel liquid chromatography-tandem mass spectrometry method for the quantitative determination of naproxen in human K2-EDTA plasma in negative ion mode was employed and validated using zidovudine as internal standard (IS). Sample preparation was accomplished by liquidliquid extraction technique. The eluted samples were chromatographed on Zorbax Eclipse XDB phenyl $4.6 \times 75 \mathrm{~mm}, 3.5 \mu \mathrm{m}$ column (Agilent Technologies) using a mobile phase consisting of acetonitrile: 20 $\mathrm{mM}$ ammonium acetate $(90: 10 \mathrm{v} / \mathrm{V})$. The injection volume was $15 \mu \mathrm{L}$ and the total run time was $3.0 \mathrm{~min}$. The method was validated for all parameters for naproxen.

Results: The method showed selectivity and linearity over a concentration range of $500.1 \mathrm{ng} / \mathrm{mL}$ to $100028.5 \mathrm{ng} / \mathrm{mL}$ The validation data indicate precision and accuracy of $90-110 \%$ and $<15 \%)$, respectively, as well as recovery (80.63\%), stability (mostly stable) and carryover (0\%).

Conclusion: $A$ rapid and selective LC-MS/MS method for the quantification of naproxen in human plasma has been developed and can be used in therapeutic drug monitoring of this drug as well as in bioequivalence studies of the drug.
\end{abstract}

Keywords: Naproxen, Therapeutic drug monitoring, Mass spectrometry, Human plasma

Tropical Journal of Pharmaceutical Research is indexed by Science Citation Index (SciSearch), Scopus, International Pharmaceutical Abstract, Chemical Abstracts, Embase, Index Copernicus, EBSCO, African Index Medicus, JournalSeek, Journal Citation Reports/Science Edition, Directory of Open Access Journals (DOAJ), African Journal Online, Bioline International, Open-J-Gate and Pharmacy Abstracts

\section{INTRODUCTION}

Naproxen (+)-2-(6-methoxy-2-naphthyl) propionic acid is a non-steroidal anti-inflammatory drug with anti-inflammatory, analgesic and antipyretic properties often preferred to acetylsalicylic acid (aspirin) because of its better absorption following oral administration and fewer adverse effects [1,2-5]. Anti-inflammatory effects of naproxen are generally thought to be related to its inhibition of cyclo-oxygenase and consequent decrease in prostaglandin concentrations in various fluids and tissues [2]. Most of its therapeutic activity is probably mediated through prostaglandin synthesis inhibition [6-8]. Several chromatographic methods have been reported for determination of naproxen in raw material [9], tablets [10-12], plasma [13-15], urine [16], intestinal perfusion samples [17] and pharmaceutical preparations [18-20]. 
The coupling of HPLC with mass spectrometry (LC-MS/MS) is now generally accepted as the preferred technique for quantitating small molecule drugs and metabolites in biological matrices, since this technique is highly selective and sensitive [21,22]. LC-MS/MS technique was successfully employed to provide a satisfactory sensitivity and selectivity in a desirable time of chromatographic run.

\section{EXPERIMENTAL}

\section{Chemicals}

Naproxen [Fig.1 (a)] was purchased from Dr. Reddy's Laboratory (Hyderabad, India) and zidovudine, the internal standard [Fig.1 (b)], from Hetero Labs Limited (Hyderabad, India). HPLC grade acetonitrile, methanol and TBME (Methyl tertiary butyl ether) were obtained from J.T. Baker. HPLC grade water was procured from Rankem pharma. Ammonium acetate was procured from Fisher scientific.
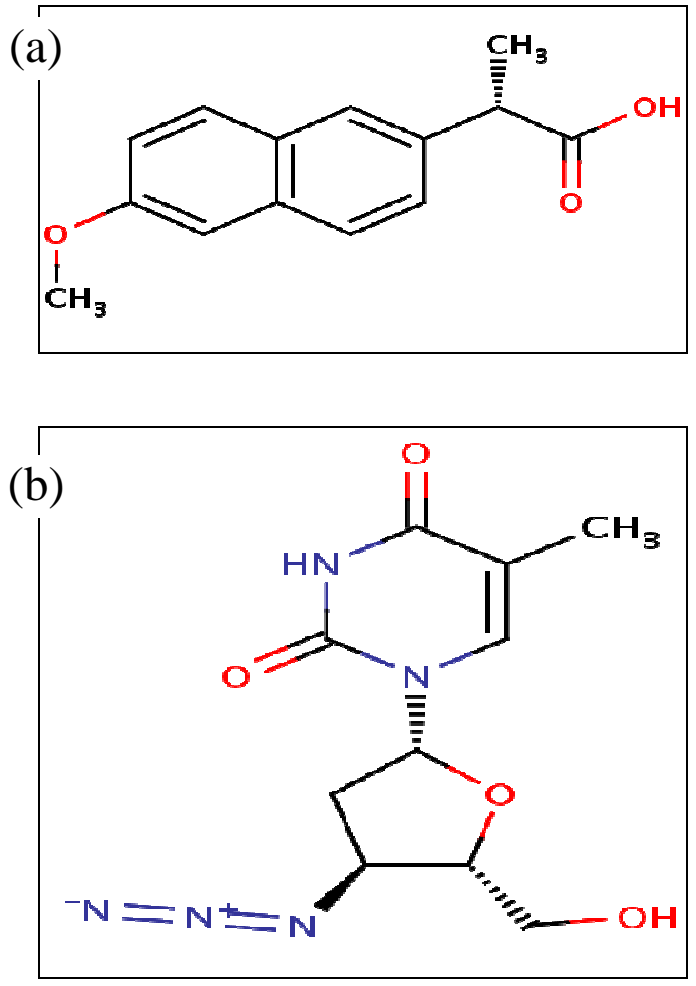

Figure 1: Naproxen (a) and Zidovudine (b)

\section{Instrumentation}

The liquid chromatographic system consist of LC Shimadzu LC10 from Shimadzu, an auto sampler of Shimadzu (SIL-HTC) coupled with an applied Biosystems SCIEX a triple quadrupole mass spectrometer (API 3000) with electrospray ionization (ESI) used for analysis. Date of acquisition and processing were controlled by Applied Biosystems/MDS SCIEX Analyst software (version 1.4.2) with Zorbax Eclipse XDB Phenyl column $(4.6 \times 75 \mathrm{~mm}, 3.5 \mu \mathrm{m})$.

\section{Bio-analytical conditions}

The chromatographic analysis was performed by using a mobile phase of HPLC grade acetonitrile: $20 \mathrm{mM}$ Ammonium acetate buffer (90:10, v/v) with flow rate $0.5 \mathrm{ml} / \mathrm{min}$ by negative ion mode (API 3000). Detection is performed by atmospheric pressure electro spray ionization (ESI) tandem mass spectrometry in negative ion mode. The chromatograms were recorded. Detection of the ions were performed by multiple reaction monitoring (MRM) of the transitions $\mathrm{m} / \mathrm{z}$ 229.0-185 for naproxen and $\mathrm{m} / \mathrm{z}$ 266.0-222.0 for the internal standard.

\section{Preparation of zidovudine stock solution}

A stock solution of Internal Standard (IS) was prepared by dissolving $5.00 \mathrm{mg}$ of zidovudine in HPLC grade methanol and made up the volume with the same in a $5 \mathrm{~mL}$ volumetric flask to produce a solution of $1000000.0000 \mathrm{ng} / \mathrm{mL}$. This solution was kept in refrigerator at $2{ }^{\circ} \mathrm{C}-8^{\circ} \mathrm{C}$. Working IS solutions were prepared by suitably diluting the above mentioned stock solution afresh before use.

\section{Preparation of naproxen stock standard and working solutions}

The naproxen stock solution was prepared by dissolving $40.00 \mathrm{mg}$ of naproxen in HPLC grade methanol and made up the volume with the same in a $10 \mathrm{~mL}$ volumetric flask to produce a solution of $4000000.0000 \mathrm{ng} / \mathrm{mL}$. This solution was kept in refrigerator at $2{ }^{\circ} \mathrm{C}-8{ }^{\circ} \mathrm{C}$. The stock solutions were diluted to suitable concentrations using diluent for spiking into plasma to obtain calibration curve (CC) standards, quality control (QC) samples for further use.

\section{Preparation of calibration curve standards and quality control (QC) samples}

Calibration curve standard consisting of a set of ten non-zero concentrations ranging from 500.1 $\mathrm{ng} / \mathrm{mL}$ to $100028.5 \mathrm{ng} / \mathrm{mL}$ of naproxen was prepared. Prepared quality control samples consisted of concentrations of $500.4 \mathrm{ng} / \mathrm{mL}$ (lower limit of quantification QC sample), 1500.1 $\mathrm{ng} / \mathrm{mL}$ (lower quality control sample), 15000.7 $\mathrm{ng} / \mathrm{mL}$ (middle quality control sample-1), 50002.2 $\mathrm{ng} / \mathrm{mL}$ (middle quality control sample-2) and $85008.8 \mathrm{ng} / \mathrm{mL}$ (higher quality control sample) for 
naproxen. These samples were stored at $-70^{\circ} \mathrm{C}$ $\pm 10^{\circ} \mathrm{C}$ until use. Twelve sets of LQC and HQC were stored at $-20{ }^{\circ} \mathrm{C} \pm 5{ }^{\circ} \mathrm{C}$ deep freezer to check $-20^{\circ} \mathrm{C}$ stability.

\section{Sample preparation procedure}

After bulk spiking, aliquots of $200 \mu \mathrm{L}$ for CCs and $200 \mu \mathrm{L}$ for QCs of spiked plasma samples were pipetted out into a pre-labelled polypropylene micro centrifuge tubes and then all the bulk spiked samples were stored to deep freezer at $70^{\circ} \mathrm{C} \pm 10^{\circ} \mathrm{C}$, except twelve replicates each of LQC and $H Q C$, which were stored in deep freezer at $-20^{\circ} \mathrm{C} \pm 5^{\circ} \mathrm{C}$ for generation of stability data at $-20{ }^{\circ} \mathrm{C}$. The thawed samples were vortexed to ensure complete mixing of the contents. $100 \mu \mathrm{L}$ of the plasma sample was pipetted into $15 \mathrm{~mL}$ glass stoppered tubes, $25 \mu \mathrm{L}$ (201592.2 ng/mL of zidovudine) internal standard spiking solution was added to it and vortexed, except in blank plasma samples where $25 \mu \mathrm{L}$ diluent was added to it and vortexed. Then 100 $\mu \mathrm{L}$ of $1 \%$ formic acid in water was added to it and vortexed. $5 \mathrm{~mL}$ of methyl tert butyl ether was added and shaken for $20 \mathrm{~min}$ on reciprocating shaker at $200 \mathrm{rpm}$. Samples were centrifuged at $4000 \mathrm{rpm}$ for $10 \mathrm{~min}$ at $4{ }^{\circ} \mathrm{C}$. Then supernatant organic layer $(4.0 \mathrm{~mL})$ was transferred to prelabelled glass dry test tubes and evaporated to dryness under gentle stream of nitrogen at 45 ${ }^{\circ} \mathrm{C}$. The samples were reconstituted in $4000 \mu \mathrm{L}$ of mobile phase and $15 \mu \mathrm{L}$ sample was injected to HPLC with MS-MS detection.

\section{Method validation}

The method was validated for selectivity, linearity, accuracy, precision, recovery, stability, and carry over test according to the principles of the FDA industry guidance.

\section{Selectivity}

At least 6 different lots of plasma were screened for the interference at the retention times of analyte(s) and internal standard using proposed extraction procedure and chromatography. One LLOQ or ULOQ extracted sample was processed from each blank. The percent interference was calculated.

\section{Linearity}

The linearity of calibration curve for naproxen was assessed at ten concentration levels in the range of $500.1 \mathrm{ng} / \mathrm{mL}$ to $100028.5 \mathrm{ng} / \mathrm{mL}$ in plasma samples. Peak area ratios for each solution against its corresponding concentration were measured and the calibration curve was obtained from the least-squares linear regression presented with their correlation coefficient.

\section{Extraction recovery}

Processed 18 blank plasma samples and reconstituted with six sets each of $4.000 \mathrm{~mL}$ of LQC, MQC2 and HQC final dilutions along with internal standard, which represent $100 \%$ extraction of analyte and internal standard (nonextracted samples). Six sets of LQC, MQC2 and HQC (7-12) samples were processed and injected (extracted samples). The extracted samples of naproxen were compared with the non-extracted samples of LQC, MQC2 and HQC. The extracted samples of internal standard were compared with the response of internal standard in the entire non-extracted eighteen quality control samples LQC, MQC2 and HQC levels. The extraction recovery at low, medium and high levels of QC samples were obtained.

\section{Accuracy and precision}

Intra assay precision and accuracy were determined by analyzing six replicates at five different QC levels in two runs on the same day. Inter-assay precision and accuracy were determined by analyzing six replicates at five different QC levels on five different runs. The acceptance criteria included accuracy within $\leq 15$ $\%$ deviation (SD) from the nominal values, except LLOQ QC, where it should be $\leq 20 \%$, and a precision of $\leq 15 \%$ relative standard deviation (RSD), except for LLOQ QC, where it should be $\leq 20 \%$.

\section{Stability}

Stability of naproxen in plasma was performed using six replicates of two QC samples at low and high levels. Samples were prepared by spiking drug-free plasma with appropriate volumes of naproxen standard solutions. The stability was evaluated with different studies such as room temperature stock solution stability, refrigerated stock solution stability, room temperature spiking solution stability, refrigerated spiking solution stability, freeze-thaw, short term stability, bench top stability, etc. Stability tests were conducted to evaluate the analyte stability in stock solutions and in plasma samples under different conditions. The stock solution stability at room temperature and refrigerated conditions (2 $8{ }^{\circ} \mathrm{C}$ ) was performed by comparing the area response of the analytes (stability samples) with the response of the sample prepared from fresh stock solution. Bench top stability (9 hrs), processed sample stability (auto sampler stability for $49 \mathrm{~h}$, freeze thaw stability (four cycles) and 
short term stability $\left(-20{ }^{\circ} \mathrm{C}\right.$ for 6 days) were performed at LQC and $\mathrm{HQC}$ levels using six replicates at each level. Samples were considered to be stable if assay values were within the acceptable limits of accuracy ( $\leq 15 \%$ $\mathrm{SD})$ and precision ( $\leq 15 \% \mathrm{RSD})$.

\section{Carryover test}

To check the carryover effect of analyte and internal standard, a suitable high concentration of calibration curve (ULOQ) of the analyte along with working concentration of the internal standard, extracted matrix blank and extracted LLOQ samples were prepared and injected.

\section{Statistical analysis}

Data analysis was carried out using ANOVA using Prism 6 software. The level of significance was set at $p<0.05$.

\section{RESULTS}

\section{Optimization of the method}

In optimizing the chromatographic conditions, the ammonium acetate buffer solution was adopted in the mobile phase of the HPLC in order to suppress the tailing phenomena of chromatographic peaks of naproxen and zidovudine. Besides, the concentration of the ammonium acetate buffer was investigated and the concentration of $20 \mathrm{mM}$ ammonium acetate made the chromatographic peaks sharp and symmetric.

Furthermore, experimental results showed that acidifying the mobile phase with formic acid also contributed to improve peak shapes of naproxen and zidovudine. Therefore, a concentration of 1 $\%$ formic acid was used in mobile phase. The acceptable retention and separation of naproxen and zidovudine was obtained by using an elution system of acetonitrile: $20 \mathrm{mM}$ ammonium acetate $90: 10, \mathrm{v} / \mathrm{v})$ as the mobile phase. The chromatogram for aqueous standard with internal standard mixture is shown in Figure 2.

The LC/MS/ MS method described here satisfies the requirement of routine analyses since it has a short run time (3.0 min), which has advantages over other methods described in the literature. Naproxen and zidovudine were retained at 1.98 and $1.74 \mathrm{~min}$ respectively in both aqueous standard and human plasma samples. Representative chromatogram of MQC2 plasma sample spiked with naproxen and IS is shown in Figure 3.

The mass parameters were optimized to obtain better ionization of naproxen and zidovudine molecules. The full scan spectrum was dominated by protonated molecules $[M+H]+m / z$ 229 and 266 for naproxen and zidovudine and the major fragment ions observed in each product spectrum were at $\mathrm{m} / \mathrm{z} 185.0$ and 222.9 respectively.

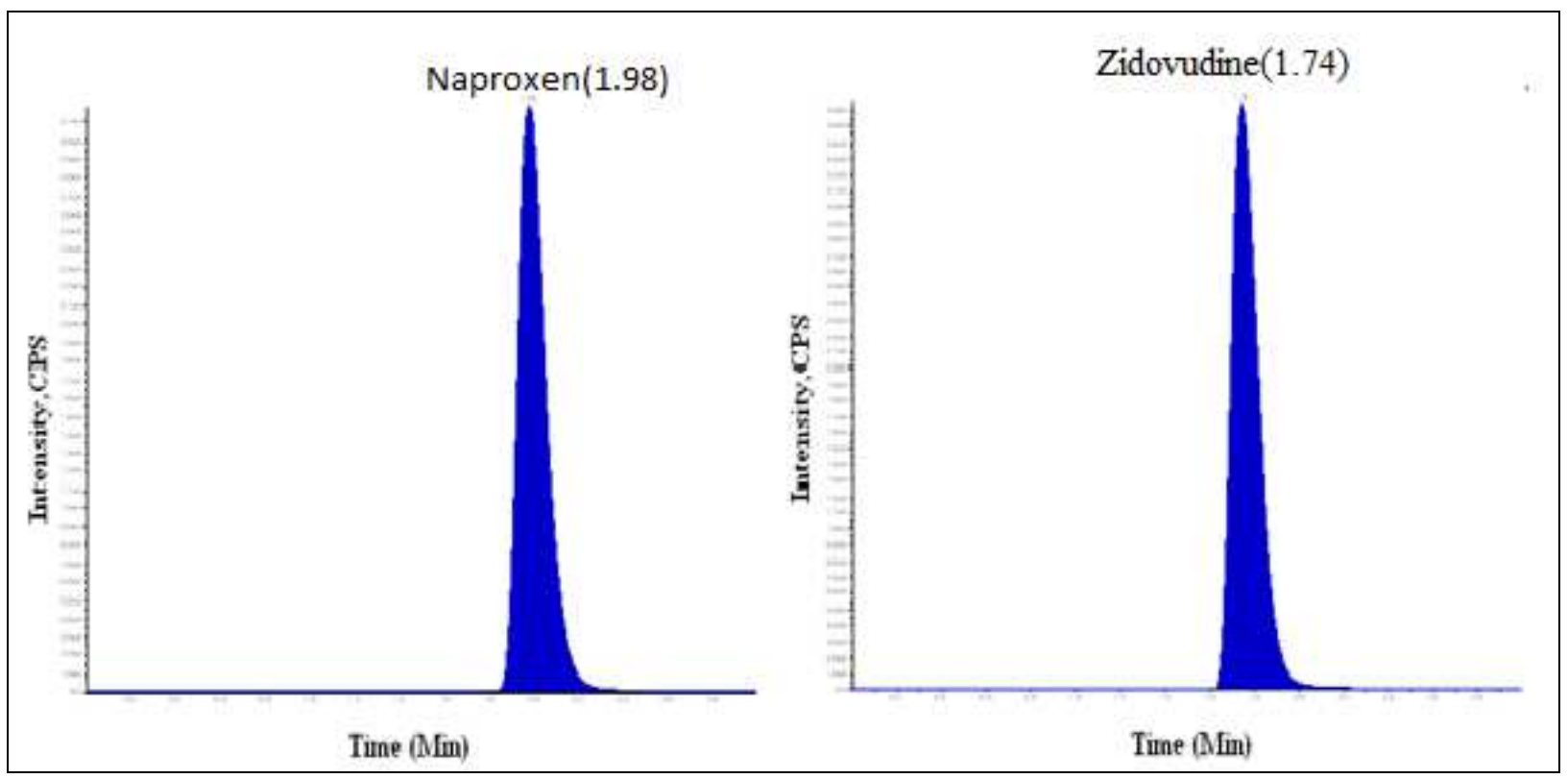

Figure 2: Representative chromatogram of an aqueous standard and internal standard mixture of naproxen 


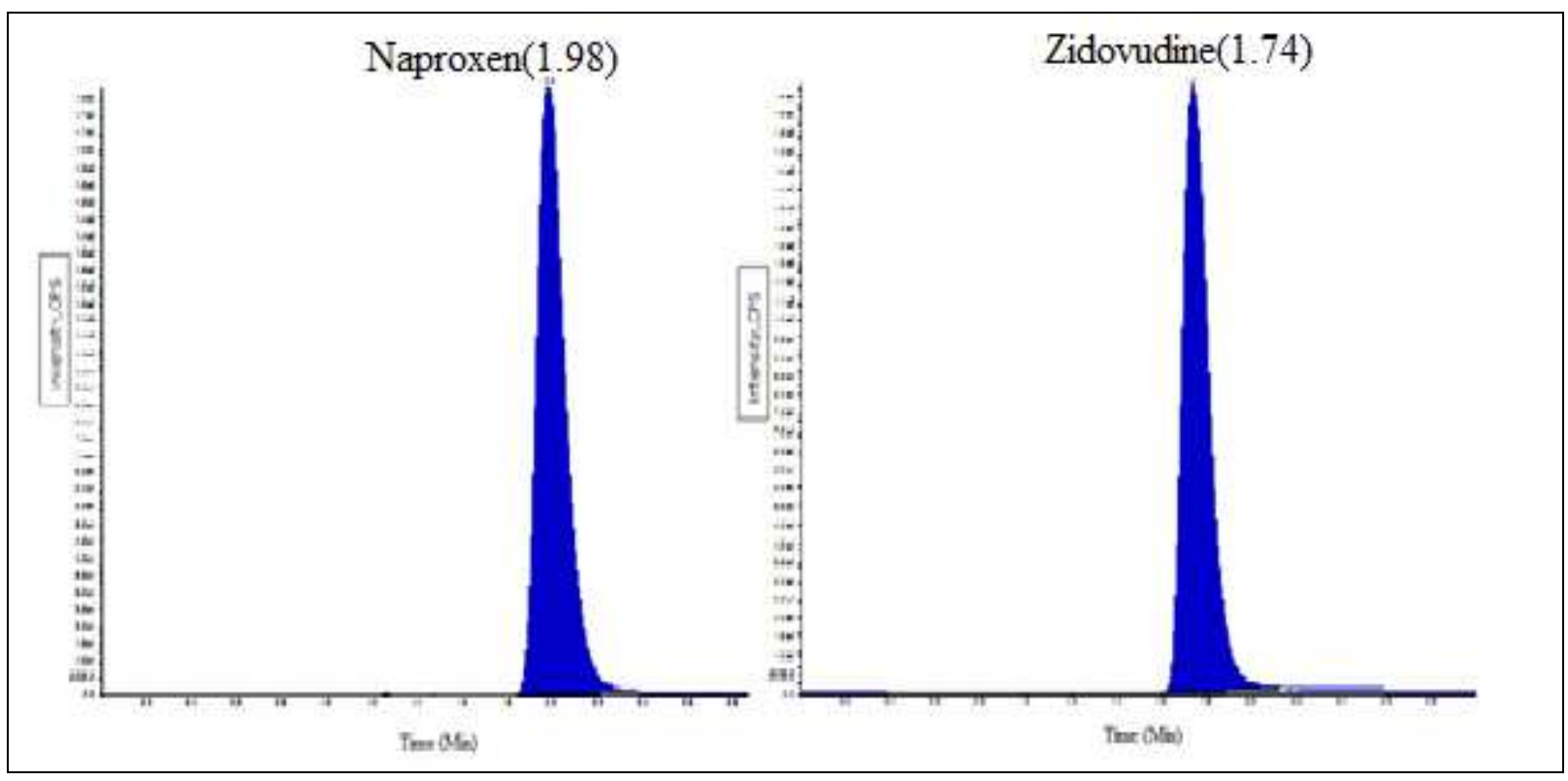

Figure 3: A representative chromatogram of MQC2 sample of naproxen with internal standard

\section{Linearity}

The correlation coefficient for naproxen over the concentration range of $500.1 \mathrm{ng} / \mathrm{mL}$ to $100028.5 \mathrm{ng} / \mathrm{mL}$ was 0.9991 . The average slope and intercept of regression equations were 0.0001 and 0.00196666 respectively. Linearity was found to be quite satisfactory and regression equation was found to be $Y=0.00001, X$ 0.0017 .

\section{Selectivity}

There was no significant interference from endogenous components observed at the mass transitions of naproxen and internal standard. For analyte selectivity, there was no significant interference observed at the retention time of analyte in six blank with internal standard sample as well as during the retention time of internal standard in all six ULOQ samples.

\section{Extraction recovery}

The percent recoveries of naproxen and zidovudine are shown in Table 1. The extraction

Table 1: Recovery of naproxen from human plasma recoveries determined were found to be between $80.63 \%$ with a precision ranging from $1.19 \%$ to $6.62 \%$ for naproxen and $81.93 \%$ with a precision ranging from $2.12 \%$ to $6.20 \%$ (Data not shown) for zidovudine respectively. The results are well within the limits.

\section{Accuracy and precision}

The intraday and inter day precision and accuracy for QCs are summarized in Table 2. The international acceptance criteria were met in each case $[19,23]$.

\section{Stability}

Stability studies play an important role in a bioanalytical method development. In this study, the stability was assessed by considering different studies such as room temperature stock solution stability, refrigerated stock solution stability, room temperature spiking solution stability, refrigerated spiking solution stability, freeze-thaw, short term stability, bench top stability, etc. The results for all stability studies were presented in Table 3.

\begin{tabular}{|c|c|c|c|c|c|c|}
\hline \multirow[b]{2}{*}{ Parameter } & \multicolumn{2}{|c|}{ LQC Response } & \multicolumn{2}{|c|}{ MQC2 Response } & \multicolumn{2}{|c|}{ HQC Response } \\
\hline & $\begin{array}{c}\text { Extracte } \\
d Q C\end{array}$ & $\begin{array}{c}\text { Unextracted } \\
Q C\end{array}$ & $\begin{array}{c}\text { Extracte } \\
d Q C\end{array}$ & $\begin{array}{c}\text { UnExtracted } \\
Q C\end{array}$ & $\begin{array}{c}\text { Extracted } \\
Q C\end{array}$ & $\begin{array}{c}\text { Unextracted } \\
Q C\end{array}$ \\
\hline CV (\%) & 6.62 & 2.68 & 3.79 & 2.13 & 3.87 & 1.19 \\
\hline Recovery (\%) & \multicolumn{2}{|c|}{73.52} & \multicolumn{2}{|c|}{80.75} & \multicolumn{2}{|c|}{87.62} \\
\hline $\begin{array}{l}\text { Overall } \\
\text { recovery }\end{array}$ & \multicolumn{6}{|c|}{$80.63 \%$} \\
\hline
\end{tabular}


Table 2: Intraday and inter day precision and accuracy results for naproxen

\begin{tabular}{lccccc}
\hline \multirow{2}{*}{ Parameter } & \multicolumn{5}{c}{ Intraday precision and accuracy for naproxen } \\
\cline { 2 - 5 } & LLOQ QC & LQC & MQC1 & MQC2 & HQC \\
\hline C.V.\% & 12.73 & 11.58 & 10.63 & 7.19 & 7.24 \\
$\%$ Nominal & 102.08 & 98.16 & 100.78 & 105.81 & 105.55 \\
\hline \multicolumn{5}{c}{} & \multicolumn{5}{c}{ Inter day precision and accuracy for naproxen } \\
\hline \% Nominal & 10.40 & 10.61 & 9.63 & 6.16 \\
& 102.00 & 100.79 & 98.22 & 104.74 \\
\hline
\end{tabular}

Table 3: Stability results of naproxen and zidovudine

\begin{tabular}{|c|c|c|c|c|}
\hline \multirow[b]{2}{*}{ Validation parameter } & \multicolumn{2}{|c|}{ Naproxen } & \multicolumn{2}{|c|}{ Zidovudine } \\
\hline & $\begin{array}{c}\% \text { Nominal } \\
/ \% \\
\text { Stability }\end{array}$ & Precision & $\begin{array}{c}\% \\
\text { Nominal/\% } \\
\text { Stability }\end{array}$ & Precision \\
\hline $\begin{array}{l}\text { Room temperature stock } \\
\text { Solution stability }(9 \mathrm{~h})\end{array}$ & $99.38 \%$ & $\begin{array}{l}1.78 \%- \\
2.13 \%\end{array}$ & $97.93 \%$ & $\begin{array}{l}3.18 \%- \\
3.84 \%\end{array}$ \\
\hline $\begin{array}{l}\text { Room temperature spiking } \\
\text { Solution stability }(9 \mathrm{~h})\end{array}$ & $98.77 \%$ & $\begin{array}{l}1.97 \%- \\
2.13 \%\end{array}$ & $99.64 \%$ & $\begin{array}{l}3.84 \%- \\
3.86 \%\end{array}$ \\
\hline $\begin{array}{l}\text { Refrigerated Stock Solution } \\
\text { Stability ( } 7 \text { days) }\end{array}$ & $102.13 \%$ & $\begin{array}{l}1.83 \%- \\
2.27 \%\end{array}$ & $104.14 \%$ & $\begin{array}{l}2.18 \%- \\
3.46 \%\end{array}$ \\
\hline $\begin{array}{l}\text { Refrigerated spiking } \\
\text { Solution stability ( } 7 \text { days) }\end{array}$ & $103.70 \%$ & $\begin{array}{l}0.66 \%- \\
2.27 \%\end{array}$ & $106.55 \%$ & $\begin{array}{l}1.80 \%- \\
2.18 \%\end{array}$ \\
\hline Auto sampler stability (49 h) & $\begin{array}{l}99.87 \%- \\
110.17 \%\end{array}$ & $\begin{array}{l}5.38 \%- \\
9.79 \%\end{array}$ & - & - \\
\hline $\begin{array}{l}\text { Freeze thaw stability ( } 4 \\
\text { Cycle) }\end{array}$ & $\begin{array}{l}108.03 \%- \\
109.72 \%\end{array}$ & $\begin{array}{l}6.43 \%- \\
8.94 \%\end{array}$ & - & - \\
\hline Bench top stability (9 h) & $\begin{array}{l}96.74 \%- \\
111.39 \%\end{array}$ & $\begin{array}{l}4.53 \%- \\
6.60 \%\end{array}$ & - & - \\
\hline $\begin{array}{l}\text { Short term }-20{ }^{\circ} \mathrm{C} \text { stability } \\
\text { ( } 6 \text { days) }\end{array}$ & $\begin{array}{c}108.63 \%- \\
110.02 \% \\
\end{array}$ & $\begin{array}{c}3.25 \%- \\
5.74 \% \\
\end{array}$ & - & - \\
\hline
\end{tabular}

\section{Carryover test}

The results demonstrate that there was no carryover effect of analyte and internal standard as the \% carry over was found to be $0 \%$.

\section{DISCUSSION}

The acceptable retention and separation of naproxen and zidovudine was obtained by using mobile phase of acetonitrile: $20 \mathrm{mM}$ ammonium acetate $(90: 10, \mathrm{v} / \mathrm{v})$. The LC/MS/ MS method described here fulfils the requirement of routine analysis as it has a short run time (3.0 $\mathrm{min})$. Representative chromatograms of an aqueous standard with internal standard mixture and plasma samples spiked with naproxen and IS were shown in Figures 2 and 3. Calibration curve of naproxen was linear over the concentration range of $500.1 \mathrm{ng} / \mathrm{mL}$ to $100028.5 \mathrm{ng} / \mathrm{mL}$ for plasma which is as good as or superior to the previous methods reported $[13,15]$.

There was no significant interference from endogenous components observed at the mass transitions of naproxen and internal standard.
Naproxen was extracted from plasma by a liquidliquid extraction procedure. This method is also the most comprehensive method which can extract naproxen in a single extraction procedure. The mean recovery is better for plasma than those of the studies from literature review.

Intra- and inter-day precision values were lower than $15 \%$. These results indicate good accuracy, precision and reproducibility of the present method.

The results presented in Table 3 show that naproxen is stable under the studied conditions, since in all cases the international acceptance criteria (variation values for area smaller than 15 $\%)$ were met [24].

The results demonstrate there was no carryover effect of analyte and internal standard.

\section{CONCLUSION}

An alternative HPLC/ESI/MS/MS method for quantification of naproxen in human plasma has been successfully developed and validated. A 
simple and inexpensive liquid-liquid extraction procedure and an isocratic chromatography condition using a reversed-phase column provided an assay well suited for real time analysis. The method exhibited excellent performance in terms of selectivity, linearity, accuracy, precision, recovery, stability and carry over test. In addition, the reported method has a short analysis run time, an advantage over previously reported methods. Therefore, this method is suitable for therapeutic drug monitoring of naproxen.

\section{ACKNOWLEDGEMENT}

The authors thank Yalamarty Pharmacy College, Tarluwada, Anandapuram, Visakhapatnam, Andhra Pradesh and Well Quest Research Laboratory (Piramal Clinical Research), Hyderabad, Andhra Pradesh for providing necessary facilities during the work.

\section{REFERENCES}

1. Mehta $P$, Sharma CS, Nikam D, Ranawat MS. Development and validation of solubility indicating uvspectrophotometric method for estimation of naproxen in pharmaceutical dosage form. Asian $J$ Biochem Pharm Res 2012; 1: 291-303.

2. Todd PA, Clissold SP. Naproxen: A reappraisal of its pharmacology, and therapeutic use in rheumatic diseases and pain states. Drugs 1990; 40: 91-137.

3. Segre E. Naproxen sodium (Anaprox): pharmacology, pharmacokinetics and drug interactions. I Reprod Med 1980; 25: 222-225.

4. Bansal V, Dex T, Proskin H, Garreffa S. A Look at the Safety Profile of Over-the-Counter Naproxen Sodium: A Meta-analysis. J Clin Pharmacol 2001; 41: 127138.

5. Martino Di, Barthelemy P, Joiris C, Capsoni ED, Masic A, Massarotti V, Gobetto R., Bini M, Martelli S. A new tetrahydrated form of sodium naproxen. $J$ Pharm Sci 2007; 96:156-167.

6. Moyer S. Pharmacokinetics of naproxen sodium. Cephalalgia 1986; 6: 77-80.

7. $L i \mathrm{JJ}$, Norton MB, Reinhard EJ, Anderson GD, Gregory SA, Isakson PC, Koboldt CM, Masferrer JL, Perkins $W E$, Seibert $K$ et al. Novel terphenyls as selective cyclooxygenase-2 inhibitors and orally active antiinflammatory agents. J Med Chem 1996; 39: 18461856.

8. Kaynak MS, Şahin S. A New HPLC Approach for Determination of in vitro Solubility of Naproxen Sodium. Harcet Univ J Facul Pharm 2008; 28: 49-62.

9. Ekpe A, Tong JH, Rodriguez L. High-performance liquid chromatographic method development and validation for the simultaneous quantitation of naproxen sodium and pseudoephedrine hydrochloride impurities. J Chromatogr Sci 2001; 39: 81-86.

10. Dinc E, Ozdemir A, Aksoy H, Ustundag O, Baleanu D. Chemometric determination of naproxen sodium and pseudoephedrine hydrochloride in tablets by HPLC. Chem Pharm Bull 2006; 54: 415-421.

11. Monser L, Darghouth F. Simultaneous determination of naproxen and related compounds by HPLC using porous graphitic carbon column. J Pharm Biomed Anal 2003; 32: 1087-1092.

12. Mitakos A, Panderi I. A validated LC method for the determination of clopidogrel in pharmaceutical preparations. J Pharm Biomed Anal 2002; 28: 431438.

13. Tashtoush BM, Al-Taani BM. HPLC determination of naproxen in plasma. Pharmazie 2003; 58: 614-615.

14. Nielsen-Kudsk F. HPLC-determination of some antiinflammatory, weak analgesic and uricosuric drugs in human blood plasma and its application to pharmacokinetics. Acta Pharmacol Toxicol 1980; 47: 267-273.

15. Phillips TM, Wellner EF. Measurement of naproxen in human plasma by chip-based immunoaffinity capillary electrophoresis. Biomed Chromatogr 2006; 20: 662667.

16. Mikami E, Goto T, Ohno T, Matsumoto $H$, Nishida $M$. Simultaneous analysis of naproxen, nabumetone and its major metabolite 6-methoxy-2-naphthylacetic acid in pharmaceuticals and human urine by highperformance liquid chromatography. J Pharm Biomed Anal 2000; 23: 917-925.

17. Zakeri-Milani P, Barzegar-Jalali M, Tajerzadeh H, Azarmi $Y$, Valizadeh $H$. Simultaneous determination of naproxen, ketoprofen and phenol red in samples from rat intestinal permeability studies: HPLC method development and validation. J Pharm Biomed Anal 2005; 39: 624-630.

18. Hsu Y, Liou Y, Lee J, Chen C. Wu A. Assay of naproxen by high-performance liquid chromatography and identification of its photoproducts by LC-ESI MS. Biomed Chromatogr 2006; 20: 787-793.

19. The United States Pharmacopeia (2006) 24th Ed., The United States Pharmacopeial Convention Inc., Rockville, MD, naproxen sodium monograph.

20. Shirode AR., Khanvilkar $V V$, Shah JM, Chitnis AP, Kotadia BV, Kadam V J. A Master Reference for Practice and Applications of Bio-analytical Method Development and Validation. J Pharm Biomed Sci 2011; 12: 1 - 9.

21. Taylor PJ. Matrix effects: the Achilles heel of quantitative high-performance liquid chromatography-electro spray tandem mass spectrometry, Clin Biochem 2005; 38: 328-334.

22. Xu RN, Fan L, Rieser MJ, El-Shourbagy TA. Recent advances in high-throughput quantitative bio analysis by LC-MS/MS. J Pharm Biomed Anal 2007; 44: $342-$ 355. 
23. Shah VP, Midha KK, Dighe S, McGilvery I, Skelly JP, Yakobi A, Layloff T, Viswanathan CT, Cook CE, McDowall $R D$ et al. Analytical Methods Validation: Bioavailability, Bio-equivalence and Pharmacokinetic Studies. Pharm Res 1992; 9: 588-592.
24. Du L, Musson DG, Wang AQ. Stability studies of vorinostat and its two metabolites in human plasma, serum and urine. J Pharm Biomed Anal 2006; 42: 556-564. 